\title{
Color Preferences for Private and Semi-private Areas in Hotels
}

\author{
Lilia R. Prado-León ${ }^{1,}$ Perla Liliana Zambrano-Prado², Susana Herrada-Rodríguez ${ }^{2,}$ \\ Sonia Felizardo-Gómez, ${ }^{1, *}$
}

${ }^{1}$ Master in Ergonomics, University of Guadalajara, México

${ }^{2}$ Architecture and Design, University Center of Art, México

Copyright $(\mathrm{C} 2018$ by authors, all rights reserved. Authors agree that this article remains permanently open access under the terms of the Creative Commons Attribution License 4.0 International License

\begin{abstract}
Soft ergonomics comprises emotional needs and other qualitative features which affect the relationship of the user to the product. In Interior Design, subjective aspects such as color preference can influence user experiences. The objective of the present study was to assess the effect of color in the choice of the interior design on private and semi-private areas of hotel areas displayed by renders and to establish whether there is a relationship between color preference and gender. This study included 197 volunteers. The experimental stimuli (nine chromatic and three achromatic) were applied to three different hotel places; all of these stimuli were presented on a computer screen, one at a time in random order. A continuous scale ranging from 0 (null liking) to 100 (absolute liking) indicated to what degree the viewer liked the image. As a whole, for all the hotel spaces, a higher preference was found for achromatic colors, especially white (74.0); even gray (57.8) surpassed the most preferred chromatic color, which was royal blue, with a score of (56.5). Some significant sex differences were distinguished in the results. These findings emphasize the importance of gaining information about color preferences in the discipline of Interior Design with the aim to satisfy users' expectations and to improve their experience.
\end{abstract}

Keywords Color Preferences, Interior Design, Private Area, Semi-private Area, Hotel Renders, Gender Differences

\section{Introduction}

In the recent years, ergonomics has been given the task to investigate the nexus between different products and the emotive relationship that they generate in the user, furthermore to other subjective and less tangible aspects such as cultural perception and the social value of the product. This trend has helped to make available information and understanding of the user needs concerning a variety of products, in addition to the traditional, strictly physical and more easily quantifiable requirements (Mcdonagh, Bruseberg \& Haslam [1]).

Soft ergonomics comprehend emotional needs and other qualitative aspects that affect the user's relationship with a given product (McDonagh-Philp \& Lebbon [2]). Included within this field are likes and dislikes of a product in terms of color.

Colors evoke various emotional feelings, such as excitement, energy, and calmness.

These feelings, evoked by either colors or color combinations, are commonly known as the color emotions and color preference is within this category (Ou, Luo, Woodcock \& Wright [3]).

\subsection{Harmony and Color Preference}

Harmony and Color Preference are concepts similarly used in the literature. Schloss \& Palmer [4], both point out that although there is a high positive correlation between them, they are however two different concepts.

Harmony refers to the matching of a color respecting to other colors, establishing a pleasant set at the sight (Parramón [5]).

Preference refers to liking or disliking feelings, e.g., a combination of colors can be harmonious but of someone's displeasure (Birren; Hayten; Fehrman \& Fehrman; Burchet $[6,7,8,9])$. However, the more harmonious is this combination the higher the likelihood to be like it.

Over the years, numerous painters and other specialists of color established principles to achieve color harmony. The laws of color harmony are divided into two main groups: 1) harmonies due to related colors, which include the combinations of colors belonging to a section of the circle of the color; and 2) accords by contrast, with color combinations of different sections regarding the circle of color.

However, these principles have not been scientifically 
proven, and the results of studies on the subject show confusing conclusions.

\subsection{Studies on Color Preference}

From the theoretical point of view, several proposals attempt to explain what type of factors are those that determine color preference. Some theories are based on biological adaptations (Hurlbert \& Ling [10]) and others on effective or emotional issues. Within the latter, the role of associations of color for the determination of preferences is highlighted.

For example, Palmer \& Schloss [11] conducted a study that found data supporting the ecological valence theory, which presents a causal explanation stating that people prefer colors strongly associated with objects they like (eg, blues with clear skies and clean water) and do not like colors related to objects they strongly dislike (e.g. browns with feces and rotten food).

In an applied approach, it has been conducted studies to determine which colors are preferred. Color preference has been assessed by the degree to which the participant likes or dislikes the color, represented by a scale with 'like' at one end and 'dislike' at the other (Hung \& Chen [12]).

Early studies to identify color preferences were carried out in isolated color, without context (Choungourian; Silver \& Ferrante; Camgöz, Yener \& Güvenç [13,14,15]). Wijk, BergSivik \& Steen [16] conducted a study in older adults and found that the order of preference was blue, green, red and brown. Fehrman \& Fehrman [8] mentioned high to low liking are the blue, red, green, purple, orange and yellow.

In Asia, blue is a beloved color as well as white (Saito; cited by Schatz y Bowers [17]).

Prado-León [18] found the following order of preference on a scale from 0 to 100 : white with a score of 71.2 , royal blue (70.2), cyan (69.6), red (66.1), black (64.6), light gray (63.4). The least preferred was the dark yellow (27.9).

Subsequently, it has been shown that there may be differences between the preferences of color stimuli isolated vs. a particular context, whether a product or an indoor space (Schloss et al. [19]).

As Schloss \& Palmer [4] mentioned, colors are rarely seen in isolation. In nature, as well as the built environment, color is influenced by the participation of one or more colors.

To that end, studies on color preference have been conducted in diverse areas of design, such as clothing, fashion accessories, computers, telephones, watches, house paint, automobiles, and interior design (Schloss et al.; Manav; Akcay et al.; Prado-León [19,20,21,22]).

Other studies have focused on finding what demographic factors are related to the preference of color: such as gender, marital status, age, educational level, profession, etc. In some of them, a significant difference in color preference according to gender has been found (Funk
\& Ndubisi [23]). Ellis \& Ficcek [24] mention that men prefer blue and women add some green.

It is therefore essential to consider the cultural and psychological characteristics of the user groups to thereby generate, through color, a positive effect on the user's perception and its interaction with the product (Sable \& Akcay; Da Silva $[25,26])$. In this sense, it is evident that studies about color preferences of different populations with different sociocultural characteristics are required.

\subsection{Preference of Color in Interior Spaces and furniture}

There are very few studies about indoor color preference, reported in the scientific literature and to a lesser extent those explicitly applied to furniture and are sometimes somewhat ambiguous (Van der Voordt, Bakker \& J. e Boon.[27]).

The evaluation of color preferences has been carried out in both private and semi-private spaces. Newman [28], mentions that semi-private areas are so characterized because of their free and open access for visitation, coexistence, and transit, wherein specific rules or limitations of behavior have to be followed; some examples of these would include lobbies, elevators, stairs, dining rooms or restaurants. Kwallek et al. [29] carried out a study of 675 subjects. The dependent variables were proofreading performance tasks, six mood states, and color preference. Independent variables were nine office colors, two saturation levels (high or low), two value levels (dark or light), warmth and coolness of the colors, and gender. Results showed that the participants preferred to work in beige and white offices instead of orange and purple color offices.

In private spaces, on the other hand, there are restrictions on access, making them personal and intimate areas, as is the case with guest rooms, or even an apartment. Some studies have evaluated both semi-private and private spaces. Both types of spaces are found in a hotel, and these themes are the competence of different types of design such as the interior, industrial and architectural.

Manav [20] conducted a study with 50 participants in Turkey, with the aim of examining the associations and color preferences considering various spaces of residences: The results indicated that for the bedroom, the color pink was preferred; for the living room, light blue; for dining area, light yellow; for children rooms, pink; for kitchen and bathroom, white, green, blue, yellow and for stair halls, light yellow.

Bakker et al. [30], conducted a very broad study, including 1095 subjects who were asked to complete a color preference questionnaire indicating their favorite color, color clothing preferences and their preferences of color in the following spaces: a) the living room, (b) the bedroom, (c) the meeting room, and (d) the office. The results showed that in the four types of rooms, the preferred 
color was white.

Van der Voordt, Bakker \& Boon [27], reported a study of 1077 Danish individuals to identify preferred colors according to different types of environments: the office and a meeting room, and two residential spaces: the living room and the bedroom. Their results showed that the color white was the most frequently mentioned as the preferred color for all areas, by a $32-44 \%$ of all male respondents and a $28-38 \%$ of all female respondents.

Ciritcioğlu, İlçe \& Burdurlu [31], conducted a study of 479 consumers from Ankara, Turkey. Preferences of three different furniture finishings were evaluated: 1) transparent finishing, 2) staining, and 3) opaque painting. Their results showed that the brown color group of wood on the furniture with transparent finishing was the most preferred group with a $29.7 \%$ and this was followed with the red and black color. Brown and its tones are the most preferred color type with a $24.7 \%$ on the applied staining; color preferences were followed by red and yellow. On the furniture surfaces coated with opaque paints, brown was the most preferred color with $24.9 \%$, and this was followed by blue and red. The color and finishing type preferences of the consumers on furniture surfaces showed a variation according to demographic characteristics: age, gender, marital status, educational level, and income level.

Studies of color preferences help to make design decisions based on empirical data; these studies provide accurate information when are carried out assessing a choice of color in a specific product or object. It is essential to take into consideration that the type of product, object and space affect the way in which the users perceive and prefer the color (Schloss et al. [19]).

The present study aimed to assess the effect of 12 different color combinations on interior design preferences for one private and two semi-private areas given by renders and to establish whether a relationship exists between color preference and gender.

\section{Materials and Methods}

This is a descriptive cross-sectional study in which subjects indicated the amount of pleasure or displeasure of the stimuli presented.

\subsection{Participants}

This study included 85 men (43\%) and 112 women (57\%) from the University Center of Art, Architecture and Design, and the University Center of Health Sciences, both centers belong to the University of Guadalajara. The men mentioned an average age of 33 years $( \pm 15)$ and the women declared an average age of $31( \pm 13)$ years.

\subsection{Inclusion Criteria}

Two criteria were determined essential for the participation of candidates for this study: 1) The absence of color blindness (normal color perception); 2) The signing of informed consent to participate in the study.

\subsection{Material and Equipment}

1) Pseudo-isochromatic color perception test films from Richmond International, INC. (Ishihara Test; Ishihara, 1960).

2) Printed informed consent.

3) 20" Apple iMac computer set to widescreen active-matrix LCD Monitor.

4) Program for the presentation of stimuli and the scale to measure preferences.

The variations in spaces in the hotel for different stimulus were: 1) the spa reception area, 2) the lobby and 3) a hotel room (suite type).

These spaces were presented with different color combinations. These combinations were based on the principle of the color harmony commonly known as Contrasting of colors with achromatic, which consists of combining achromatic colors (white, black or gray) with chromatic colors (Pawlik [32]).

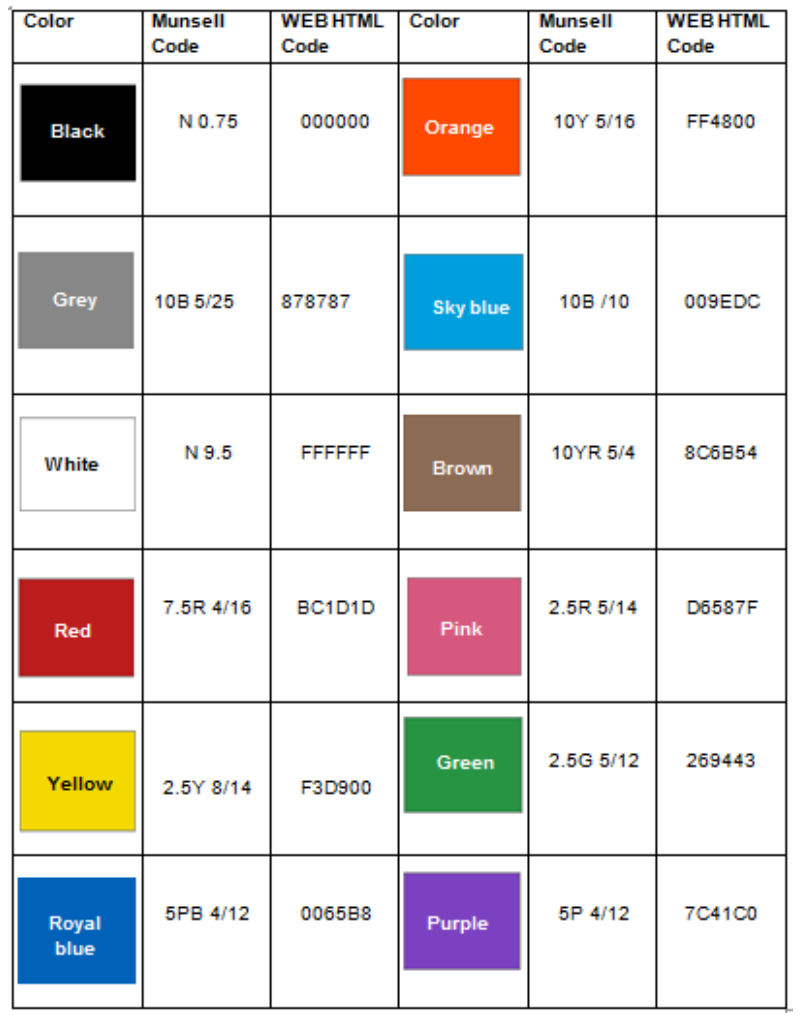

Source: own elaboration

Figure 1. Code of colors applied to furnitures in spaces given by the render

This principle was chosen because several studies have reported the preference of white or close to white (light gray or beige) in various interior spaces (Kwallek et al., Bakker et al. [29,30]). However, spaces have ceilings, walls, floors, furnitures, curtains, accessories, etc., and all 
in the same color (white, gray or beige), is improbable to occur in a real interior space; therefore, by applying this principle, the walls, ceilings, and floors were presented in white or gray achromatics and the colors of the furnishings were those varying according to the pattern shown in Figure 1: three of them are achromatic colors (gray, black and white) and nine are chromatic colors (orange, red, royal blue, yellow, cyan, purple, brown, green and pink). When the achromatics were used in the furniture, some element of color was added either in walls or accessories, or using the natural color of the wood, so that the principle was retained, but the color prevailing in the furniture.

\subsection{Procedure}

Once the participants signed the consent form, they were instructed to not using any music devices, such as iPods and to turn off their cell phones. The participants proceeded to enter a booth made of an aluminum frame with thick black curtains hung on it, the design of the enclosure prevented the passage of light, and otherwise light might cause a color bias perception. A computer, a desktop, and chair were placed inside the booth.

The posture and position of the participants were adjusted so that the distance from the monitor to the participant was the equivalent to the length of their arms extended forward, sitting in the chair with the participant's back in a neutral position (the wheels of the chair allowed the participant to move closer or further away). Using the height adjustment mechanism of the chair, the participant's vision was aligned with the height of the upper part of the monitor.

After the participant's posture and position were adjusted, it was verified if they had understood the instructions. Once the experiment began, the images used for testing were presented on the computer screen, by using a program designed to show the stimuli one by one. The order of presentation was randomized for each subject and was different for each participant. At the bottom of the screen, there was a scale of preference perception ranging from 0 (null liking) to 100 (absolute liking). The participants selected their answer by clicking the mouse.

The database was created with Microsoft Office Excel (Mac OS X, version 15), and the SPSS program (Mac OS X, version 22) was used for statistical analysis. The Kolmogorov-Smirnov test was used to verify the normal distribution of preference data; as the data did not have a normal distribution, the Kruskal Wallis test was used to identify differences between the groups. Mann Whitney's U-test was used for comparison between pairs of colors and gender.

\section{Results}

Of the 197 participants, only one was unable to complete the tests for the preference for the lobby and hotel suite; hence, at the end of the study, data from 196 subjects tabulated for the three were hotel spaces. None of the participants were rejected because of color blindness.

\subsection{Hotel Spa Reception Area}

Significant differences were found in the overall appreciation for each color as reported by the 196 participants (Kruskal Wallis, mean rank difference: $\mathrm{H}=$ 403.257, $P<0.001$. Mann Whitney's U-test was performed to determine the difference between pairs of colors. White (See Figure 2) was the most colored significantly preferred $(P<0.001)$ than the other 11 colors; followed by gray with a higher rating $(P=0.039)$ than these 8 colors: purple, green, brown, yellow, orange, red, royal blue, and black.

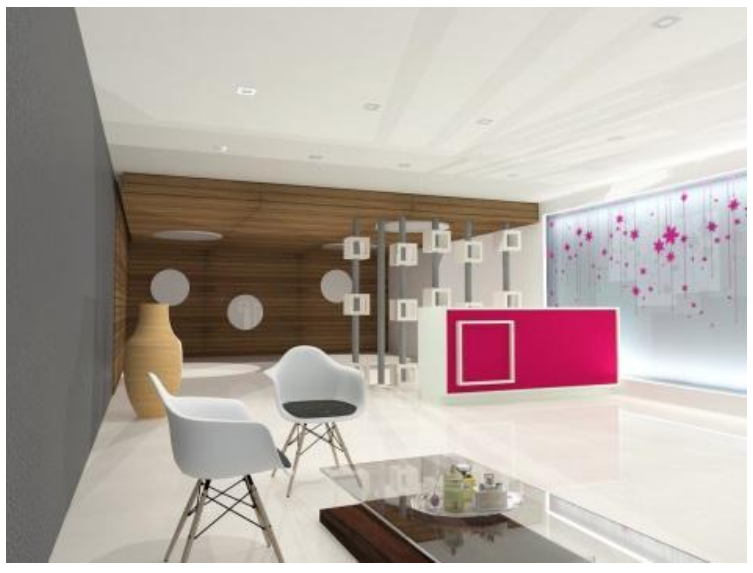

Source: Alondra Diaz Yepez. Unpublished

Figure 2. Spa reception area in the color white

A comparison by gender was made for each color using Mann Whitney U test (the distribution of preferences was not normal). Significant differences were found in only three colors: orange $(\mathrm{U}=3764.5, P=0.012)$ was preferred more by men $(\bar{X}=32.38)$ than by women $(\bar{X}=23.85)$; white $(\mathrm{U}=3883.0, P=0.026)$ was preferred more by women $(\bar{X}=87.34)$ than men $(\bar{X}=80.12)$, and purple $(\mathrm{U}=$ $3746.5, P=0.010)$ was preferred more by men $(\bar{X}=36.02)$ than women $(\bar{X}=25.91)$.

\subsection{Hotel lobby}

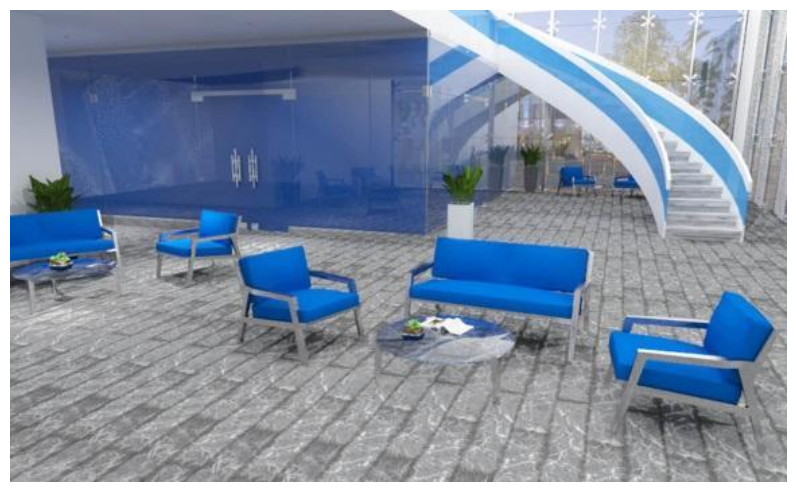

Source: Carolina Nuñez Gúzman. Unpublished

Figure 3. Hotel lobby in royal blue color 
Royal blue color (See Figure 3) showed the greatest significant difference $(P<0.001)$ with a higher preference rating than the other 11 colors. It was followed by grey $(P=$ $0.037)$ and with a similar rating were found the black $(\bar{X}=$ $55.4)$, red $(\bar{X}=52.5)$ and white $(\bar{X}=50.9)$ colors $(P=$ 0.002 ), all with a higher rating than the remaining less preferred colors (purple, green, pink, brown, yellow and orange).

In terms of gender comparison, the only significant difference was found for color purple preference $(\mathrm{U}=$ $3750.5, P=0.014)$, more preferred by men $(\bar{X}=27.44)$ than by women $(\bar{X}=16.98)$.

\subsection{Hotel suite}

White (See Figure 4) was the only one color that showed a significant difference (a higher preference rating, $P<$ 0.001 ) with respect to the other 11 colors. It was followed in preference by grey, brown, and red colors, which all received higher preference ratings than the other eight colors (purple, green, pink, yellow, orange, cyan, black, and royal blue).

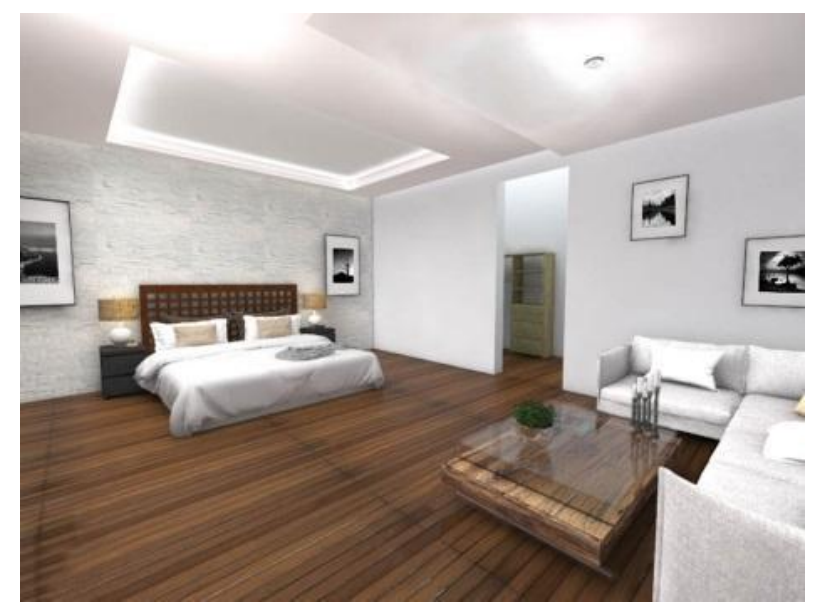

Source: Carolina Nuñez Gúzman. Unpublished

Figure 4. Hotel suite in the color white

No significant gender differences were found for color preference in this case. The $\bar{X}$ of the color preference ratings according to space/situation is presented in Table 1 , and the $\bar{X}$ of the color preference rating by gender is presented in Table 2.

Table 1. Mean color preferences according to spaces

\begin{tabular}{|c|c|c|c|c|c|c|c|c|c|c|c|c|}
\hline Space & Orange & Red & $\begin{array}{c}\text { Royal } \\
\text { Blue }\end{array}$ & White & Brown & Cyan & Yellow & Grey & Black & Purple & Pink & Green \\
\hline $\begin{array}{c}\text { Spa } \\
\text { Reception } \\
\text { Area }\end{array}$ & 27.5 & 40.2 & 42.5 & 84.2 & 39.1 & 44.3 & 40.1 & 54.5 & 25.6 & 30.3 & 42.5 & 27.0 \\
\hline Lobby & 35.7 & 52.5 & 86.6 & 50.9 & 32.5 & 44.4 & 33.8 & 57.9 & 55.4 & 21.5 & 25.8 & 26.9 \\
\hline $\begin{array}{c}\text { Hotel } \\
\text { Suite }\end{array}$ & 39.5 & 55.6 & 40.6 & 87.0 & 62.1 & 39.6 & 35.6 & 61.1 & 37.7 & 22.6 & 33.4 & 24.8 \\
\hline Total $\bar{X}$ & 34.2 & 49.4 & 56.5 & 74.0 & 44.5 & 42.7 & 36.5 & 57.8 & 39.5 & 24.8 & 33.9 & 26.2 \\
\hline
\end{tabular}

Table 2. Mean color preference by gender

\begin{tabular}{|c|c|c|c|c|c|c|c|c|c|c|c|}
\hline Gender & Orange & Red & $\begin{array}{l}\text { Royal } \\
\text { Blue }\end{array}$ & White & Brown & Cyan & Yellow & Grey & Purple & Pink & Green \\
\hline Men & & & & & & & & & & & \\
\hline $\bar{X}$ & 39.45 & 60.24 & 87.16 & 63.64 & 41.8 & 37.05 & 38.91 & 64.64 & 39.91 & 32.58 & 28.61 \\
\hline $\mathrm{n}$ & 85 & 85 & 85 & 85 & 85 & 85 & 85 & 85 & 85 & 85 & 85 \\
\hline Women & & & & & & & & & & & \\
\hline $\bar{X}$ & 39.54 & 52.10 & 36.7 & 86.83 & 60.95 & 38.0 & 34.55 & 36.78 & 20.09 & 34.10 & 21.80 \\
\hline $\mathrm{n}$ & 111 & 111 & 111 & 111 & 111 & 111 & 111 & 111 & 111 & 111 & 111 \\
\hline Total & & & & & & & & & & & \\
\hline $\bar{X}$ & 39.50 & 55.63 & 40.57 & 86.98 & 62.11 & 39.6 & 35.64 & 61.12 & 37.70 & 33.44 & 24.76 \\
\hline $\mathrm{n}$ & 196 & 196 & 196 & 196 & 196 & 196 & 196 & 196 & 196 & 196 & 196 \\
\hline
\end{tabular}

\section{Discussion}

In the general comparison between colors, there was a higher frequency of preference (concerning other colors) for achromatic colors; in both semi-private spaces (spa reception and hotel lobby) and private spaces (suite-type rooms), white and grey were specifically preferred.

No studies have evaluated preferences with the color combinations of this study, so the comparisons given below, are not entirely comparable.

However, the preference of white and gray in our study, suggests the use of achromatics in inside buildings is preferred in various types of interior spaces (Kwallek et al., Bakker et al. [29,30]).

It also coincides with the claim that larger surfaces are favored by lighter tones and smaller components by darker tones and by the fact that white and gray were the colors applied to ceilings, walls and floors, being of greater extent than the furniture (Wagner, Kilincsoy \& Vink [33]). 


\subsection{Preferences of Color on Isolated Stimuli and Context: The Meaning of Color}

Palmer and Schloss [34], found a fundamental difference: for isolated stimuli (given to the persons in a color square palette) people preferred saturated and bright colors and when the colors were tested on automobiles, the most appreciated were the achromatic ones: black, gray and white. So the color preference is different regarding context.

Manav [20] declares that people prefer room colors according to with their desired feeling when inhabiting the room: e.g., light blue is preferred for the living room because it feels calm; whereas "near white," green, blue, and yellow are preferred for the bathroom as they think they are more hygienic and pure.

This tendency to associate meanings with preferences is supported by Yildirim et al. [35], who found in their study that achromatic colors as being more associated with calm and peacefulness and therefore, if it is desired that spacious interiors could be seen as, restful, quiet, and peaceful, achromatic colors are preferred.

In this regard, the preference for achromatic colors in these spaces may be related to the subjective meaning of color. In the specific case of the spa reception area, where white and grey were the colors significantly preferred ( $\mathrm{p} \leq$ 0.05 ) in comparison to other 11 colors; it seems clear that in the space of this nature, the activities related to health and cleanliness are carried out. In this case, white was associated with these meanings (Prado-León, Ávila-Chaurand \& Rosales-Cinco [36]).

Kaya \& Crosby [37] found, in their hospital study, that the color white was second in preference, showing similarity to what was observed in this study in the case of the SPA, which, while not exactly a hospital setting, is somewhat related.

In the case of the hotel lobby, even though white was among the preferred colors, the color that had a significantly higher preference score $(\mathrm{p} \leq 0.05)$ about the other 11 colors, was royal blue.

This result coincides once again with Kaya \& Crosby [37] in which blue had been selected as the first-place choice for a hotel, followed by grey, orange, and green.

Likewise, the color blue was preferred in the context of evaluations of isolated stimuli (without applying colors to specific objects) according to the results obtained by (Schloss et al. [19]). Similarly, in the present study, a significant preference for color royal blue was showed.

The preference showed by the color blue may be related to the high number of positive emotions it has presented in other studies such as the investigation of Kaya \& Epps [38].

The fifth most liked color in the three areas average was brown, but showed no significant difference. This color has already been indicated as preferred in furniture, regardless of the type of surface finish (Ciritcioğlu, Ilce, Burdurlu [31].
Also, in the particular case of brown, there are signs of previous studies that although brown is never named as a favorite color in isolated stimuli, it is preferred for furniture, floors, and carpets indoors, because of its association with natural materials such as wood, which has historically been a material used in interior design $([39,40,41,42])$.

\subsection{Gender Differences}

The results of this investigation showed differences in color preference by both genders, in the case of semi-private spaces; these differences were identified for three of the twelve colors, observing that men demonstrated a preference for the color orange in the reception area of the spa and for purple in this same area as well as in the lobby of the hotel, unlike the women. The above is similar to what Schloss et al., Prado-León, Funk \& Ndubisi [19, 22, 23] pointed out.

In as much as the private space, concerning to the hotel suite, no gender differences were presented; being the white the most preferred color by both gender. This result coincides with those of (Yildirim et al. [35]), in which no gender differences were reported regarding emotional and spatial qualities evoked by achromatic colors.

It should be noted that the observed gender differences, reinforce the need to obtain this kind of data considering gender on color preferences when designing semi-private and private spaces so that the user expectations are met, and their interactive experiences within these spaces are enhanced.

The results of this study confirm the proposals of Eroglu \& Machleit [43] who say that in the study of preferences within spaces, an understanding of the color emotions is essential, especially in term of liking and disliking opinions because this can have effects on the clients.

It is necessary to clarify that color is not the only element that can create ambiance in a space, given those other sensory elements such as music, aroma, temperature, and design also play a part (Das; Van Rompay et al.; Beverland et al.; Levy \& Weitz; Turley \& Milliman; Gorn et al., Bitner) cited in Cho \& Lee [44]. However, one of the essential elements - and the first element identified within a visual composition _is color (Felizardo [45]).

Also, since the chromatological aspects of color are largely determined by socio-cultural factors, it is important to undertake these studies in different cultures, in order to become familiar with the user data and to have the ability to generate positive aspects for the interaction of the space with the customer (Akcay, Sable, \& Dalgin [46]).

It is important to mention that the investigation of color preferences need to be unceasing, given the phenomenon of globalization and all of the socio-cultural changes it entails (Ackay et al., Park \& Guerin [21,47]).

\section{Conclusions}

The results obtained and expounded in the present 
document have established, in a general way that the colors of highest preference, from the most to least preferred, are white, gray, blue, red, and brown.

Although most of the combinations were not classified as the best liked, it highlights the combination in which predominantly the white achromatic, in some furnitures, ceilings, floors and walls, was the color that got a significant higher score (near to 75). In this combination, but to a lesser extent, gray and brown were reported as preferred in interior design and furniture (Ciritcioğlu, Ilce, Burdurlu, Kaya \& Crosby [31, 37].

Followed the preference score for white (74.0), other colors approached the rating of 50, which might suggest that the degree of preference would be neutral. Apparently, preference reports generally do not show very high scores. For example, in a previous study similar (Prado[18]) results were observed (the highest was white with a 71.2). Also, the percentages of preferences highlighted as the most preferred by Bakker et al. \& Ciritcioğlu, İlçe \& Burdurlu [30,31], fluctuated between 24.7-38\% of respondents; therefore, less than 50 percentages are seen as the highest preferences for a given color. On the other hand, the results reported in this study refer to the most liked in a comparative sense based on the scores of the scale and highlighting those that showed a significant difference.

Using the scale from 0 to 100 is an appropriate way to test the preference of color because it allows identifying the degree of preference more accurately than in the traditional method in which the participant is only asked to choose the most likable color.

The results of analysis by gender showed significant differences in preference for some colors (except in the case of the suite). It is, however, important to note that the majority of the gender differences were encountered in colors which were not preferred to a statistically significant degree (orange and purple), therefore, these results must be taken with care.

Furthermore, as we compared types of spaces (semi-private vs. private), it was observed that, in as much as color preferences varied with differing products or environments, these useful data could be taken into account in design decisions for such spaces and products.

The interior spaces are made up of many elements, such as walls, ceilings, floors, curtains, furniture accessories, etc. The selection of colors and furnishings spaces confronts a fundamental problem to solve, taking into account the user preference, and to date, there are insufficient data to clarify this issue

This study did not intend to determine which color should be utilized in these types of spaces; instead, the objective was to generate recommendations and guidelines to provide data useful to elucidate the principles of color harmony applied to interior spaces and to explore the application of methods for the analysis of color preferences. In this sense, this study has helped to expand the stage of the study of color preferences in interior design, currently being a very few explored field, then contributing to the knowledge and understanding in this area of research.

These new findings highlight the need to obtain data on color preferences for specific products or spaces, to meet the requirements for an attractive design proposal. In this sense, future research should include investigate other established principles of harmony through the experts in color and into the discipline of interior design.

\section{REFERENCES}

[1] D. Mcdonagh, A. Bruseberg \& C. Haslam. Visual product evaluation: exploring users' emotional relationships with products. Applied Ergonomics, v. 33, n. 3, p. 231-240, 2002.

[2] D. Mcdonagh-Philp \& C. Lebbon. The Emotional Domain in Product Design. The Design Journal, v. 3, n. 1, p. 31-43, 2000.

[3] L. Ou, M. Luo, A. Woodcock and A. Wright, "A study of colour emotion and colour preference. Part III: Colour preference modeling", Color Research \& Application, v. 29, n. 5, p. $381-389,2004$

[4] K. Schloss and S. Palmer, "Aesthetic response to color combinations: preference, harmony, and similarity", Attention, Perception, \& Psychophysics, v. 73, n. 2, p. 551-571, 2011.

[5] Parramón, Teoría y práctica del color, 7th ed. Barcelona: Parramón Ediciones, 1998.

[6] F. Birren, New horizons in color. New York: Reinhold, 1955.

[7] P. Hayten, El color en la publicidad y las artes Gráficas, 3rd ed. Las Ediciones de Arte, 1978, 1978.

[8] K. Fehrman and C. Fehrman, Color: el secreto y su influencia. México: Pearson Educación, 2001.

[9] K. Burchett, "Color harmony", Color Research \& Application, v. 27, n. 1, p. 28-31, 2001.

[10] A. Hurlbert and Y. Ling, "Biological components of sex differences in color preference", Current Biology, v. 17, n. 16, p. R623-R625, 2007.

[11] S. Palmer and K. Schloss, "An ecological valence theory of human color preference", Proceedings of the National Academy of Sciences, v. 107, n. 19, p. 8877-8882, 2010.

[12] W. Hung \& L. Chen. Exploring relationships between product aesthetics, typicality and preference. Proceedings of the 3rd IASDR Conference on Design Research. 2009.

[13] A. Choungourian, "Color Preferences and Cultural Variation", Perceptual and Motor Skills, vol. 26, no. 3, pp. 1203-1206, 1968.

[14] N. Silver and R. Ferrante, "Sex Differences in Color Preferences among An Elderly Sample", Perceptual and Motor Skills, v. 80, n. 3, p. 920-922, 1995.

[15] N. Camgöz, C. Yener and D. Güvenç, "Effects of hue, 
saturation, and brightness on preference", Color Research \& Application, v. 27, n. 3, p. 199-207, 2002.

[16] H. Wijk, S. Berg, L. Sivik and B. Steen, "Colour discrimination, colour naming and colour preferences among individuals with Alzheimer's disease", International Journal of Geriatric Psychiatry, v. 14, n. 12, p. 1000-1005, 1999.

[17] S. Schatz and C. Bowers, "10 Questions on Room Color: Answers for Workplace Designers", Ergonomics in Design: The Quarterly of Human Factors Applications, v. 13, n. 4, p. 21-27, 2005.

[18] L. Prado-León. Preferencias del color: una comparación entre el estímulo aislado y aplicado a objetos. In G. Ortiz Hernández \& B. Solórzano Palomares, Tópicos del color en México y el mundo (1st ed., pp. 15-30). México D.F: Universidad Autónoma Metropolitana, 2014.

[19] K. Schloss, E. Strauss \& S. Palmer. Object color preferences. Color Research \& Application, v. 38, n. 6, p. 393-411, 2012.

[20] B. Manav. Color-emotion associations and color preferences: A case study for residences. Color Research \& Application, v. 32, n. 2, p. 144-150, 2007.

[21] O. Akcay \& M. Dalgin, S. Bhatnagar. Perception of Color in Product Choice among College Students: A Cross-National Analysis of USA, India, China and Turkey. International Journal of Business and Social Science, v. 2, n. $21,2011$.

[22] L. Prado-León. Color Preferences in Household Appliances: Data for Emotional Design. Procedia Manufacturing, v. 3, p. 5707-5714, 2015.

[23] D. Funk and N. Oly Ndubisi, "Colour and product choice: a study of gender roles", Management Research News, v. 29, n. 12 , p. 41-52, 2006.

[24] L. Ellis and C. Ficcek, "Color preferences according to gender and sexual orientation", Personality and Individual Differences, v. 31, n. 8, p. 1375-1379, 2001.

[25] P. Sable \& O. Akcay. Color: Cross Cultural Marketing Perspectives as to what Governs our Response to it, Proceedings of ASBBS, 17 (1), 950-954, 2010.

[26] F. Da Silva. ColorErg-Color Ergonomics in Fashion Design. Advances in Ergonomics in Design, Usability \& Special Populations, v. 16, n. 1, p. 88, 2014.

[27] T. van der Voordt, I. Bakker and J. de Boon, "Color preferences for four different types of spaces", Facilities, vol. 35, no. 34, pp. 155-169, 2017.

[28] O. Newman. Defensible space. New York: Macmillan, p. 264,1972

[29] N. Kwallek et al. Effects of nine monochromatic office interior colors on clerical tasks and worker mood. Color Research \& Application, v. 21, n. 6, p. 448-458, 1996.

[30] I. Bakker, T. van der Voordt, P. Vink, J. de Boon and C. Bazley, "Color preferences for different topics in connection to personal characteristics", Color Research \& Application vol. 40, no. 1, pp. 62-71, 2013.

[31] H. Ciritcioğlu, A. İlce and E. Burdurlu, "The color preferences of consumers on furniture surfaces", The Online Journal of Science and Technology, vol. 7, no. 3, pp.
98-108, 2017.

[32] Pawlik, Teoría del color, 1st ed. Barcelona: Paidós, 1996.

[33] A. Wagner, Ü. Kilincsoy and P. Vink, "Visual customization: Diversity in color preferences in the automotive interior and implications for interior design", Color Research \& Application, v. 43, n. 4, p. 471-488, 2018.

[34] S. Palmer and K. Schloss, "Color preference", Encyclopedia of Color Science and Technology. Springer Science+Business Media New York 2015, New York, 2015.

[35] K. Yildirim, M. Hidayetoglu \& A. Capanoglu. Effects of Interior Colors on Mood and Preference: Comparisons of Two Living Rooms. Perceptual and Motor Skills, v. 112, n. 2, p. 509-524, 2011.

[36] L. Prado-León, R. Avila-Chaurand \& R. Rosales-Cinco. Colour associations in the Mexican university population. Progress in Colour Studies: Volume II. Psychological aspects, p. 189-202, 2006.

[37] N. Kaya, M. Crosby. Color associations with different building types: An experimental study on American college students. Color Research \& Application, v. 31, n. 1, p. 67-71, 2006.

[38] N. Kaya \& H. Epps. Relationship between color and emotion: A study of college students. College Student J, v. 38, n. 3, p. 396, 2004.

[39] C.B. Holmes, J.A.B. Buchanan. Color preference as a function of the object described. In: Society P, ed. Bulletin; v. 22 , p. $423-425,1984$.

[40] A. Fenko, J.J. Otten, H.N. Schifferstein. Describing product experience in different languages: the role of sensory modalities.J Pragmatics. v. 42, p. 3314-3327, 2010.

[41] P. Hekkert, E. Karana. Designing material experience. Mater Exp Fundament Mater Des. 2013;1.

[42] R. Gagg. Basics interior architecture 05: Texture1 materials. Muttenz, Switzerland: Ava Publishing; 2012.

[43] S. A. Eroglu \& K. A. Machleit. An empirical study of retail crowding: Antecedents and consequences. Journal of Retailing, 201-221, 1990.

[44] J. Y. Cho \& E. J. Lee. Impact of Interior Colors in Retail Store Atmosphere on Consumers' Perceived Store Luxury, Emotions, and Preference. Clothing and Textiles, 33-48, 2017.

[45] S. Felizardo. Efecto de los colores en la percepción de emociones y cualidades espaciales en un diseño de sala y cocina (Tesis de maestría). Universidad de Guadalajara, Jalisco, México, 2018.

[46] O. Akcay, P. Sable \& M. Dalgin. The importance of color in product choice among young Hispanic, Caucasian, and African-American groups in the USA. International Journal of Business and Social Science, v. 3, n. 6, 2012.

[47] Y. Park \& D. Guerin. Meaning and Preference of Interior Color Palettes among Four Cultures. Journal of Interior Design, v. 28, n. 1, p. 27-39, 2002. 